\title{
Lipid profile in minor thalassemic patients: a historical cohort study
}

\author{
Hashemieh $\mathrm{M}^{1}$, Javadzadeh $\mathrm{M}^{2}$, Shirkavand $\mathrm{A}^{3}$, Sheibani $\mathrm{K}^{4}$ \\ ${ }^{I}$ Department of Pediatric Hematology \& Oncology, Imam Hossein Medical Center, Shahid Beheshti \\ University of Medical Sciences, ${ }^{2}$ Department of Pediatric Neurology, Shahid Beheshti University of \\ Medical Sciences, ${ }^{3}$ Tehran University of Medical Sciences, ${ }^{4}$ Clinical Research and Development \\ Center, Imam Hossein Medical Center, Shahid Beheshti University of Medical Sciences
}

\begin{abstract}
Minor beta thalassemia is a disorder without any special symptom which only causes mild anemia. In thalassemic patients accelerated erythropoiesis and enhanced cholesterol consumption have been suggested as the dominant mechanism for low level of lipoproteins. Hyperlipidemia is a risk factor for cardiovascular diseases and hence, low level of serum lipids can act as a protective factor. Because of the differences between social, economic, cultural conditions, dietary habits and genetics patterns among Iranians with other nations, this survey was conducted to verify these parameters among our thalassemia minor subjects. This study was carried out on 100 thalassemia carriers and 200 normal controls. Blood samples were collected and the biochemical evaluation was performed for measuring serum total cholesterol, LDL, HDL, TG, VLD. Descriptive statistical tables, independent t-test, MannWhitney and Chi-square were used for analyzing the data. The average values of serum total cholesterol, TG, LDL, HDL and VLDL in thalassemia minor subjects were 163.63 \pm 34.28 , $159.74 \pm 157.54,90.97 \pm 23.94,34.97 \pm 8.07$ and $73.44 \pm 72.43 \mathrm{mg} / \mathrm{dl}$ respectively. Moreover, the mean levels of total cholesterol, TG, LDL, HDL and VLDL in normal subjects were 192.77 \pm 37.27 , $155.67 \pm 109.58,123.42 \pm 33.57,38.02 \pm 15.6$ and $71.57 \pm 50.5 \mathrm{mg} / \mathrm{dl}$ respectively. The amount of serum total cholesterol and LDL in thalassemia carriers was significantly lower than normal subjects that shows the potential decline of cardiovascular and brain vessels diseases among thalassemia minor subjects compared to control group while other factors between the two groups did not show any significant difference.
\end{abstract}

\section{Introduction}

Beta-thalassemia is an inherited hemoglobin disorder caused by impaired synthesis of the beta globin chain. The excess unmatched alpha chains accumulate in the growing erythroid precursors and in adult red blood cells causing ineffective erythropoiesis and hemolysis ${ }^{1}$. In beta thalassemia trait, one of the two beta globin genes is abnormal but the lack of beta globin is not great enough to cause problems in the normal functioning of the hemoglobin. A person with this condition simply carries the genetic trait for beta thalassemia and will usually experience no health problems other than a mild anemia ${ }^{2}$. It is well established that beta thalassemia has a major impact on plasma lipids and lipoproteins ${ }^{3}$. In severe beta thalassemia (thalassemia major and intermedia), hypocholesterolemia caused by a marked reduction of both LDL and HDL has been consistently reported $^{3-7}$; in parallel, in beta thalassemia carriers (thalassemia minor), total cholesterol and LDL levels tend to be lower than those found in age and sex-matched controls ${ }^{6,7}$. A wide study conducted in the Sardinian population not only proved that beta thalassemia carriers have a lower total and LDL cholesterol level than do controls but also showed a small but significant reduction of apoB and apoA-I levels and borderline changes in lipid and protein composition in LDL and $\mathrm{HDL}^{8,9}$. It has been suggested that the mild hypocholesterolemia found in carriers of beta thalassemia might contribute to the protection of these individuals from the development of premature coronary artery disease $(C A D)^{10-15}$. Retrospective studies show that the prevalence of thalassemia carriers among patients with myocardial infarction was much less than expected ${ }^{10}$ and that in some samples with beta thalassemia minor, myocardial infarction occurs ten years later than in non-thalassemic subjects ${ }^{12}$. Despite these studies, similar research had not been performed in Iranian population. Since socioeconomical and cultural conditions in addition to the life style (particularly dietary habits) and genetic patterns of Iranian population may be different from other nations, we decided to study the TG and cholesterol levels among Iranian minor thalassemic patients. To achieve this goal, we investigated the cholesterol, triglyceride, HDL, 
LDL, and VLDL in beta thalassemia carriers in Arak (a city in central part of Iran with a population of more than one million).

\section{Materials and Methods}

The present study was carried out in September 2005 as a historical cohort. We enrolled 100 thalassemia carriers who were mainly parents of thalassemia major patients referred to Amirkabir hospital (a general hospital in Arak city) for routine blood transfusion. Two hundred normal controls of matched age and gender were also enrolled in the study; who were parents of other hospitalized children in that hospital. Minor thalassemia was confirmed using $\mathrm{CBC}$, serum iron, TIBC and hemoglobin electrophoresis tests.

The number of enrolled participants was adequate to evaluate differences between the investigated parameters, achieving statistical power $>0.80$ at $<0.05$ probability level.

In the control group, the presence of minor thalassemia was evaluated by a CBC test and hemoglobin electrophoresis. In the case of proved minor thalassemia, they were excluded from control group and other normal cases were substituted. Informed consent was obtained from all participants. The study protocol was approved by the ethics committee of Arak Medical University. All participants were interviewed by trained personnel and filled out standardized questionnaires which included demographic characteristics like age and gender, in addition to the history of cardiac or cerebral ischemia in their families.

3-5 $\mathrm{ml}$ venous blood samples were collected in plain tubes in a sitting position after 12 hours of fasting. Biochemical tests (serum total cholesterol, LDL, HDL, TG, VLDL) were measured in the laboratory. Biochemical determination of LDL and HDL was done using Randex kit (England), while TG and serum total cholesterol levels were measured by biochemical kit (Iran). VLDL was estimated using this formula (VLDL=TG/2.175).

Descriptive statistical tables, independent t-test, Mann-Whitney and Chi-square tests were used for analyzing the data. P-values less than 0.05 were considered significant. SPSS software (version 13.0, SPSS Co, Chicago IL) was used for the statistical analysis.

\section{Results}

Our case group included 100 patients (41 males and 59 females, mean age $37.5 \pm 13.4$ ) with diagnosis of minor thalassemia, while our control group included 200 normal subjects (96 males and 104 females, mean age $39.6 \pm 10.3)$. Demographic findings are summarized in table I.

Statistical results of serum lipid analysis in thalassemia carriers and control group indicated significant difference of serum total cholesterol $(\mathrm{p}<0.001)$ and LDL $(\mathrm{p}<0.001)$ between groups while there were no significant differences between other values (table II). We found a statistically significant difference between serum total cholesterol $(\mathrm{p}<0.001)$ and LDL $(\mathrm{p}<0.001)$ levels of male patients and male controls (table III). We also found a similar pattern among females (cholesterol $\mathrm{p}=0.008$ and LDL $\mathrm{p}<0.001$ ). The results are presented in table IV.

By analyzing the results of serum lipid values in both groups with mean age lower than 25 years, no statistically significant difference was found (table V). In contrast, there was statistically significant difference between both serum total cholesterol and LDL in the patients with mean age of 26-40 years $(p<0.001)$ and only between LDL in the patients with mean age higher than 41 years $(p=0.004)$. These results have been summarized in tables VI and VII respectively.

Table I: Patients' distribution according to the age \& diagnosis status

\begin{tabular}{|c|c|c|c|c|c|}
\hline \multirow{2}{*}{\multicolumn{2}{|c|}{ Parameter }} & \multirow[b]{2}{*}{ Total } & \multicolumn{2}{|c|}{ Group } & \multirow[t]{2}{*}{$\mathrm{P}$} \\
\hline & & & Control & $\begin{array}{l}\text { Thalasse } \\
\text { mia Minor }\end{array}$ & \\
\hline Number & & 300 & 200 & 100 & \\
\hline $\begin{array}{l}\text { Sex, M/F } \\
(\mathrm{M} \%)\end{array}$ & & $\begin{array}{c}137 / 163 \\
(46 \%)\end{array}$ & $\begin{array}{c}96 / 104 \\
(48 \%)\end{array}$ & $\begin{array}{l}41 / 59 \\
(41 \%)\end{array}$ & $0.251^{*}$ \\
\hline \multirow[t]{4}{*}{ Age } & & $38.9 \pm 11.4$ & $39.6 \pm 10.3$ & $37.5 \pm 13.4$ & $0.134 \dagger$ \\
\hline & $\leq 25$ & $25(8.4 \%)$ & $8(4 \%)$ & $17(17.3 \%)$ & \\
\hline & $26-40$ & $134(45 \%)$ & $76(38 \%)$ & $58(59.2 \%)$ & \\
\hline & $\geq 41$ & $139(46.4 \%)$ & $116(58 \%)$ & $23(23.5 \%)$ & \\
\hline
\end{tabular}

* Based on Chi-square test, $\dagger$ Based on t-test

Table II: Plasma Lipid Values in minor thalassemia and normal patients

\begin{tabular}{cccccc}
\hline & \multicolumn{2}{c}{ Normal } & \multicolumn{2}{c}{ Minor Thalassemia } & P value \\
\hline & Mean & S.D & Mean & S.D & \\
Chol & 192.77 & 37.27 & 163.6 & 34.28 & $<0.001 \dagger$ \\
TG & 155.67 & 109.58 & 159.74 & 157.54 & N.S* $\neq$ \\
LDL & 123.42 & 33.57 & 90.97 & 23.94 & $<0.001 \dagger$ \\
HDL & 38.02 & 15.6 & 34.97 & 8.07 & N.S $\ddagger$ \\
VLDL & 71.57 & 50.5 & 73.44 & 72.43 & N.S $\ddagger$ \\
\hline
\end{tabular}

Table III: Plasma Lipid Values in minor thalassemia and normal male subjects

\begin{tabular}{clcccc}
\hline & \multicolumn{2}{c}{ Normal } & \multicolumn{2}{c}{ Minor Thalassemia } & \multirow{2}{*}{ P value } \\
& Mean & S.D & Mean & S.D & \\
\cline { 1 - 5 } Chol & 195.23 & 42.04 & 150.27 & 26.71 & \\
TG & 168.17 & 146.12 & 153.93 & 207.99 & N.S $\ddagger$ \\
LDL & 125.171 & 35.99 & 85.07 & 20 & $<0.001 \dagger$ \\
HDL & 39.15 & 21.26 & 33.17 & 8.76 & N.S $\ddagger$ \\
VLDL & 77.31 & 67.18 & 70.77 & 95.62 & N.S $\ddagger$ \\
\hline
\end{tabular}


Table IV: Plasma Lipid Values in minor thalassemia and normal female subjects

\begin{tabular}{cccccc}
\hline & \multicolumn{2}{c}{ Normal } & \multicolumn{2}{c}{ Minor Thalassemia } & P value \\
& Mean & S.D & Mean & S.D & \\
\hline Chol & 190.5 & 32.5 & 172.86 & 36.07 & $0.008 \dagger$ \\
TG & 144.13 & 58.87 & 163.78 & 111.75 & N.S $\neq$ \\
LDL & 121.31 & 31.37 & 95.07 & 25.71 & $<0.001 \dagger$ \\
HDL & 36.98 & 7.33 & 36.22 & 7.38 & N.S $\neq$ \\
VLDL & 66.26 & 27.06 & 75.3 & 51.37 & N.S \\
\hline
\end{tabular}

Table V: Plasma Lipid Values in minor thalassemia and normal patients with age range $<25$ years

\begin{tabular}{cccccc}
\hline & \multicolumn{2}{c}{ Normal } & \multicolumn{2}{c}{ Minor Thalassemia } & P value \\
& Mean & S.D & Mean & S.D & \\
\hline Chol & 163.75 & 39.55 & 154.18 & 27.96 & N.S $\dagger$ \\
TG & 112.5 & 32.46 & 112.65 & 45.98 & N.S $\neq$ \\
LDL & 96.75 & 42.78 & 81.59 & 19.09 & N.S $\dagger$ \\
HDL & 41.25 & 21.4 & 46.35 & 7.2 & N.S $\neq$ \\
VLDL & 51.72 & 14.92 & 51.79 & 21.14 & N.S $\neq$ \\
\hline
\end{tabular}

Table VI: Plasma Lipid Values in minor thalassemia and normal subjects with age range $26-40$ years

\begin{tabular}{cccccc}
\hline & \multicolumn{2}{c}{ Normal } & \multicolumn{2}{c}{ Minor Thalassemia } & P value \\
& Mean & S.D & Mean & S.D & \\
\hline Chol & 194.08 & 36.69 & 159.83 & 34.63 & $<0.001 \dagger$ \\
TG & 173.39 & 147.4 & 167.4 & 183.24 & N.S $\ddagger$ \\
LDL & 125.66 & 32.82 & 89.71 & 24.61 & $<0.001 \dagger$ \\
HDL & 36.66 & 7.64 & 33.81 & 7.38 & N.S $\neq$ \\
VLDL & 79.72 & 67.77 & 76.96 & 84.24 & N.S $\neq$ \\
\hline
\end{tabular}

Table VII: Plasma Lipid Values in minor thalassemia and normal subjects with age range $>40$ years

\begin{tabular}{cccccc}
\hline & \multicolumn{2}{c}{ Normal } & \multicolumn{2}{c}{ Minor Thalassemia } & P value \\
& Mean & S.D & Mean & S.D & \\
\hline Chol & 193.91 & 37.34 & 180.91 & 34.34 & N.S $\ddagger$ \\
TG & 147.03 & 79.89 & 178.65 & 144.09 & N.S $\neq$ \\
LDL & 123.79 & 33.29 & 101 & 23.7 & $0.004 \dagger$ \\
HDL & 38.69 & 18.93 & 37.04 & 10.23 & N.S $\neq$ \\
VLDL & 67.6 & 36.73 & 82.13 & 66.25 & N.S $\neq$ \\
\hline
\end{tabular}

$*$ N.S=not significant, $†$ Based on t-test

\$ Based on Mann-Whitney test

\section{Discussion}

Studies have confirmed that lipid and lipoprotein abnormalities play a major role in the pathogenesis and progression of atherosclerosis and cardiovascular diseases. These chronic diseases have become a growing health problem worldwide $^{7}$. In this study we evaluated several blood lipids and lipoproteins in a population of Iranian beta thalassemia minor and normal subjects. It was found that thalassemia minor patients had lower total cholesterol and LDL cholesterol levels than normal controls. These results are in consistent with the Mailoli et al. findings 5 .

It has also been reported that HDL-cholesterol, TG and VLDL show no significant difference in thalassemia minor subjects compared to normal population $^{7,14}$. In the current study, we found no statistically significant difference in TG, HDL and VLDL among thalassemia minor patients compared to control group which is in line with other studies.

In our study serum lipid values in patients with mean age lower than 25 years, indicated no significant difference with controls while significant differences between both serum total cholesterol and LDL in patients with mean age of 26-40 years and only between LDL in the subjects with mean age higher than 41 years was found.

In conclusion, the concentration of some fractions of serum lipids which in thalassemia carriers are below the normal levels can potentially reduce the risk of cardiovascular diseases. The Lipid-lowering effect of beta-thalassemia trait in minor thalassemia raises the question as to whether this effect might slow down the progression of coronary diseases and delay the occurrence of myocardial infarction in these patients. The answer to this question requires more prospective studies on patients with beta-thalassemia trait.

\section{Acknowledgement}

The authors would like to thank Dr. Mozhgan Sadeghi Mahani for her invaluable help and support in data collecting and performing necessary analysis.

\section{References}

1. Schrier SL, Angelucci E. New strategies in the treatment of the thalassemia. Annu. Rev. Med. 2005; 56: $157-71$.

2. Cappellini M.D, Cohen A, Eleftheriou A, Piga A, Porter J, Taher A. Guidelines for the clinical management of thalassaemia, second edition 2008: $10-20$

3. Deiana L, Garuti R, Pes GM, Carru C, Errigo A, Rolleri M, Pisciotta L, Masturzo P, Cantafora A, Calandra S, Bertolini S. Influence of beta( 0$)$ thalassemia on the phenotypic expression of heterozygous familial hypercholesterolemia : a study of patients with familial hypercholesterolemia from Sardinia, Arterioscler Thromb Vasc Biol. 2000; 20(1): 236-43.

4. Giardini O, Murgia F, Martino F, Mannarino O, Corrado G, Maggioni G. Serum lipid pattern in betathalassemia. Acta Haematol. 1978;60:100 -107. 
5. Maioli M, Cuccuru GB, Pranzetti P, Pacifico A, Cherchi GM. Plasma lipids and lipoproteins pattern in beta-thalassemia. Acta Haematol. 1984; 71(2):106110.

6. Goldfarb AW, Eliezer A, Rachmilewitz A, Eisenberg $\mathrm{S}$. Abnormal low and high density lipoproteins in homozygous beta-thalassaemia. $\mathrm{Br} \mathrm{J}$ Haematol. 1991;79(3):481-6.

7. Amendola. G, Danise. P, Todisco. N, Durzo. G, Diplama. A,Diconilio. R, Lipid profile in Beta-thalassaemia intermedia patients: correlation with erythroid bone marrow activity, Int $\mathbf{J}$ Lab Hematol. 2007; 29(3):172-6.

8. Maioli M, Pettinato S, Cherchi GM, Giraudi D, Pacifico A, Pupita G, Tidore MG. Plasma lipids in beta-thalassemia minor. Atherosclerosis. 1989; 75(23):245-8.

9. Maioli M, Vigna GB, Tonolo G, Brizzi P, Ciccarese M, Donega P, Maioli M, Fellin R. Plasma lipoprotein composition, apolipoprotein(a) concentration and isoforms in b-thalassemia. Atherosclerosis. 1997; 131(1):127-33.

10. Wang $\mathrm{CH}$, Schilling RF. Myocardial infarction and thalassemia trait: an example of heterozygote advantage. Am J Hematol. 1995; 49(1):73-5.
11. Tassiopoulos T, Stamateolos G, Zakopoulos N, Fessas P, Eliopoulos GD. Low incidence of acute myocardial infarction in beta-thalassaemia trait carriers. Haematologia (Budap). 1995; 26(4):199-203.

12. Gallerani M, Scapoli C, Cicognani I, Ricci A, Martinelli L, Cappato R, Manfredini R, Dall'Ara G, Faggioli M, Pareschi PL. Thalassemia trait and myocardial infarction: low infarction incidence in male subjects confirmed. J Intern Med. 1991; 230(2):109-11.

13. Aessopos A, Farmakis D, Deftereos S, Tsironi M, Tassiopoulos S, Moyssakis I and Karagiorga M. Thalassemia Heart Disease: A Comparative Evaluation of Thalassemia Major and Thalassemia Intermedia. Chest. 2005; 127(5):1523-30.

14. Hartman C, Tamary H, Tamir A, Shabad E, Levine C, Koren A, Shamir R. Hypocholestrolemia in children and adolescent with beta thalassemia. J Pediatr. 2002; 141(4):543-7.

15. Papanastasiou DA, Siorokou T, Haliotis FA. betaThalassaemia and factors affecting the metabolism of lipids and lipoproteins. Haematologia (Budap) 1996; 27(3):143-53. 